\title{
On Specialization, Divergence and Evolution: A Brief Response to Ron Martin's Review
}

\author{
Regional Studies, DOI: 10.1080/00343404.2016.1183975 \\ Michael Storper, Tom Kemeny, Naji P. Makarem, Taner Osman
}

We thank Ron Martin for his insightful review essay on our book. Ron Martin has, as always, raised many of the issues that are central to understanding the development pathways of regions and to structuring research to generate robust insights that could be useful in sustaining or creating prosperous, inclusive regions. It is therefore a pleasure to be able to engage with his discussion in a way that hopefully will help us all to move forward collectively

First, we agree with Ron Martin that research on regional development should be securely anchored in both theory and data. We respectfully disagree with his remark that our book is light on detailed data analysis. One of our major intentions in this book was to test a wide variety of explanations of regional growth and decline by marrying rigorous theory to as much data as possible, whether the issue be one of hard regional economics or "softer" institutional factors. To this end, the book is built upon what we believe to be an exhaustive, and at times innovative body of data-driven scholarship about our two metropolitan areas. Our study of each region's economic base and labor market is based on dis-aggregations of published data that are more detailed than in any other published study of two cities. This dis-aggregation method allow original empirical insights into specialization, labor demand, labor supply, skills, wages and task structures. For some of our labor and housing market analyses, we used detailed micro-data. Further, to our knowledge, there exists no comparable analysis of the structure of two big cities' civic and economic networks. The comprehensive and unique work in the book on innovation networks, entrepreneurialism, social capital, public spending are all rely heavily on original data analysis. We also undertake a detailed, historical content analysis of discourses and narratives about economic development in each region - a first for the literature. And finally, our extensive historical, qualitative and interview data, complement this wealth of quantitative material. In short, in the urban and regional economic development literature, we know of no equivalent integration of this wealth of original evidence on two cities.

Second, Ron Martin raises the centrally important issue of the role of specialization in economic development today. In the cases at hand, we show that specialization leads to high regional incomes, in the past and in the present. Ron Martin seems to suggest that regional economic diversification might be a key to high income. The debate about specialization versus diversification suffers from both conceptual confusion and weak empirics. Kemeny and Storper (2014) report on some original econometrics that suggest that specialization and economic 
development are connected today. In this book, we define specialization in a way that avoids the often confusing use of the term in much of the literature.

Martin also brings up the technical issue of how to measure specialization. We take this on (and draw on it in our book) in Kemeny and Storper (2014) as well. Specialization is a combination of a high share of an activity in the economy, but in very large economies, it can be large absolute size, and in many economies it is therefore a combination of both. Los Angeles is no longer specialized; we call it a "fuzzy" economy. We report on shares of employment that are measured with much more care than is common in the literature. We decomposed tradable industries into six-digit subsectors and then added them up, carefully excluding heterogeneous sub-sectors. We reported the direct employment shares using this laborious and original disaggregation technique, as just one of the many detailed data analysis exercises that underpin our book. Each of these sectors has upstream and downstream direct multipliers as well as indirect home market multipliers. So, to take on Martin's point, a 10\% share for information technology in the SF Bay Area economy using our technique is extremely high. It is overwhelmingly important to that region and it is the principal reason why it is the wealthiest metro area in the United States of America. We suspect that if our methods were applied to a wide variety of cities, it would be seen that specialized cities today are more prosperous that diversified ones, and in addition, that specialization has become more important in the new economy since the late $20^{\text {th }}$ century than it was in the 1970 s an issue to which we return below.

Beyond these measurement issues, Martin takes a stance that diversification spreads risk and makes economies more resilient over the long run. We agree that there is a dearth of empirical support for this notion, even though it has been around for decades. The essential conceptual issue here is to specify the period over which diversification supposedly makes economies more resilient, and to demonstrate, with careful controls on directions of causality, that it really leads to better regional economic performance over the long run. It does seem that if diversification as a key to long-term prosperity were so convincing, surely someone would have found a way to demonstrate its veracity with rigorous empirics by now.

In any case, the way to shed light on this debate is to look at economic development over time, the way we do in this book. Market capitalism goes through periods in which dominant industries shift, as in the transition from what is vernacularly called the "old economy" to the "new economy" in the 1970s and 1980s. In the 1960s, across the developed world, the geography of the old economy was the geography of a set of mature, mainly manufacturing industries. Rates of innovation in these industries had slowed, and they were far down their product cycles. As a consequence, they were generally suburbanizing and progressively leaving high-income cities for national peripheries. By the 1980s they were offshoring in earnest, headed to the developing world. This process manifested itself in a decline in manufacturing employment. The geography of the end of the old economy was one that produced the declines of many center cities, the decline of old manufacturing metropolitan economies, and a broad trend to inter-regional income convergence. It also led to diversified economies, because those economies 
basically mixed up pieces of mature industries rather than concentrating the core activities of specific industries.

But since the 1980s or so, specialization and divergence are back and so are cities. This is because the new economy is propelled by a set of still-innovative sectors that have strong agglomeration economies - activities like information technology, life sciences, and financial services. They favor particular city-regions and within them central locations. This structures the geography of development and incomes today. The high-income city-regions of the world are specialized. Cityregions that are moving up the development ladder become more specialized. By contrast, like many city-regions in the 1970s, the city-regions today that are lower down the income ladder are more diversified because they are getting the maturing and de-agglomerating pieces of both old and new economy industries. They are specialized in "tasks" not in outputs, unlike high-income regions that host clusters and specialized in sets of outputs.

The point is that it is fruitless to have a debate over any putative timeinvariant virtues of either specialization or diversification. They can only be understood over time, in light of broad tendencies of the economy-wide phases of development (eg old economy to new economy), and over space in terms of the economy-wide division of labor and how it evolves over the life of the economywide dynamic. It's not inconceivable that as the new economy as a whole matures, we will shift (in relative terms) out of cities, and back toward convergence again. But convergence is usually sign of stagnation of the economy as a whole, because it reflects a relative diminution of the innovative, clustered side of the economic dynamic in favor of maturity, slowdown in productivity growth and geographical evening out. This is the geographical and temporal texture to the age-old equity versus growth tensions that are written into market capitalism.

In any case, in the period we examine in this book, specialization is the name of the game for high-income city-regions, but the problem is that we cannot successfully predict, as the economy shifts periods of development, exactly which cities will end up successfully specialized and hence successful at economic development as high-wage, high-income regions.

Martin also raises a reformulation of the specialization and diversification question by evolutionary economic geography. Here, it is proposed that economies diversify in a narrow band of "related" activities, and also that economies evolve gradually over time. Echoing the points above, we feel that this proposal, as some kind of sweeping time-and-space eternal lesson about economic development, is the wrong way to go. First of all, we note that up to now, most measures of "relatedness" are circular because they just use existing census categories (e.g. two activities are related because they are both four-digit industries within a three-digit division). This merely reflects some kind of census division's conventional wisdom. Moreover, our detailed empirical evidence goes against grain of this assumption. When we decomposed the IT industries, for example, we found extreme heterogeneity between the four- and five-digit NAICS information technology sectors between Los Angeles and San Francisco (apples and oranges, as we would say). When we got down to six-digit dis-aggregations, we showed that the high-tech 
agglomerations of the two areas are not comparable. We triangulated this with detailed occupational data showing that even within six-digit occupations, there are wage differences of $20-50 \%$ between the two regions in the core trade-able industries. So, in the terminology of evolutionary economic geography, they seem "unrelated" to one another even though the census assigns them the same industry.

By the same token, the economy has ensembles of functions that can be closely related in ways that census categories will not capture. For example, in contemporary high technology, the fortunes of lawyers, investment bankers, VCs and programmers are all intertwined if they are related through input-output linkages and dependent on the same source of demand, the same innovative dynamics, the same regional price system. They do not make for a diversified regional economy, because they are part of a interdependent eco-system. This is not "related diversity," but specialization. Evolutionary economic geography is just now starting to come up with truly 'independent' indices of relatedness (using patent data for the most part), and we await the operationalization of relatedness in a way that would shed some more light on this important issue.

More importantly, in our analysis of LA and San Francisco, we find that the two economies started with certain factor endowments, but did not evolve smoothly into related activities. This is especially true for LA, which had the world's biggest endowments of STEM workers, PhD engineers and firms in semiconductor and communications guidance system (relying on semiconductors as early as the 1950s) in the world. The LA economy didn't evolve into related sectors, because those sectors re-defined themselves into a new market structure and set of business models and organizational practices that LA's firms were unable to master. San Francisco's economic actors had a positive rupture: they invented these new practices, both in IT and in biotech a bit later on.

This is again, a major point of our book. This two-city city comparison is an illustration of a wider economic and geographical dynamic: when capitalism changes phase (old economy to new economy in this case), relatedness and gradual evolution are often pushed aside as dominant principles of economic development, at least in the major winner regions. It is their ability or inability to invent and reinvent ways of doing things that determines whether their factor endowments and organizations will be moved into whatever the new economy is at any time. Again, and in line with what we say about diversification above, as the innovative phases of the economy come to a close, and it enters into broad maturity dynamics, then gradual evolution may indeed be what economies come to be dominated by. This may indeed already be going on in the Bay Area now, almost a half-century into the new economy. But it is not what made the West Coast of the USA into what it is. It was these dynamics of rupture that generate turbulence in the fates of cities that made LA fall so far down the ladder of American metro regions (as well as Detroit and other cities). This rupture happened earlier to Boston, which was not even in the top ten American metro areas by income in 1970, and is now in the top 5, as it came back not through gradual evolution into industries related to its old mill 
economy, but through complete self-reinvention. San Francisco and Boston were not "adaptive." In Europe's more sluggish innovation economy and with Europe's sluggish demography, such dynamics of turbulence, rupture and reinvention may not be as clearly in evidence as in the USA, but they are certainly in apparent at a global scale. But when one looks at the top tier cities in Europe and the old manufacturing regions, they seem similar, if less dramatic cases of such turbulence and rupture as we see in the USA. So, to fully understand a particular period's pattern of uneven economic development, we need to grasp at least two important but distinctive dynamics: (1) gradual evolution (especially in period of technological maturity), as well as (2) radical ruptures in the organization of capitalism, the latter being captured by unexpected locations that are then propelled from lower to higher development (income) 'clubs.'

To conclude, we thank Ron Martin for his attention to the issues we have raised. In this brief response, we have urged that economic geography look beyond binaries of specialization/diversification, evolutionary/rupture, related/unrelated, in order to weave these into a narrative that sees each in relation to larger spacetime dynamics - of innovation, clustering, maturity and de-agglomeration - that drives global patterns of divergence and convergence. Our book, just because of the empirical material of two regions entering the new economy, is a story of divergence and turbulence. We think it is a convincing one.

\section{References}

Kemeny, T., \& Storper, M. (2015). Is specialization good for regional economic development? Regional Studies, 49(6), 1003-1018. 